\title{
Polymer-based Engineering for High-efficiency Plastic Dye-sensitized Solar Cells
}

\author{
Tsutomu Miyasaka and Masashi Ikegami \\ Graduate School of Engineering, Toin University of Yokohama, \\ Yokohama, Kanagawa 225-8502, Japan \\ Email:miyasaka@cc.toin.ac.jp
}

\begin{abstract}
Material engineering for fabrication of flexible dye-sensitized solar cells using plastic film substrates and printable materials are reviewed. Electrochemically active mesoporous layers are prepared both on the working photo-electrode (nanocrystalline $\mathrm{TiO}_{2}$ ) and counterelectrode (catalyst) by low-temperature coating of printable pastes containing nano-particles. Polymer conductive materials are successfully used as cathode catalysts loaded on the conterelectrode and as carrier transport-rectifying materials for use in solidification of electrolyte in combination with carbon materials. Performances of plastic solar cells are discussed with respects to the structure of the mesoporous films, light-harvesting functions of dyes, and design of printed counterelectrode. Commercial advantages of the lightweight, flexible cell in power generation are also introduced based on proof-of-concept tests with large-area integrated modules.
\end{abstract} Keywords: plastic, printing, conductive polymer, $\mathrm{TiO}_{2}$, dye, sensitizer, photovoltaic, module

\section{Introduction}

The technology of dye-sensitized solar cell (DSSC) has achieved conversion efficiency of $11 \%$ [1-3] and more by improvement of dye sensitizers and light-harvesting structures of semiconductor mesoporous layers. The efficiency is comparable with those of thin amorphous silicon solar cells and twice more than those recently achieved with organic photovoltaic cells (around 6\%). Most of high-efficiency DSSCs have concerned use of mesoporous $\mathrm{TiO}_{2}$ as a stable semiconductor and $\mathrm{Ru}$ bipyridyl complex dyes as sensitizers [4]. Although the efficiency, as well as the durability, of the DSSC is still not surpassing the level of other solid-state junction type solar cells (crystalline silicon and CIGS, etc), a strong merit of DSSC over the solid-state cells has been emphasized on account of its low-cost manufacturing feasibility without use of the high vacuum and nano-scale manipulation for junction structures. This merit is also concluded for comparison with organic photovoltaic cells; the latter requires precise control for active layers' thickness on nanometer scale. It is significant for realizing a simple coating process for active layer preparation that a relatively thick layer $(5-20 \mu \mathrm{m})$

Received April

6,2010

Accepted May

7,2010 can be applied for photoelectric generation. This is the case for DSSC.

For practical applications, proof-of-concept studies of DSSC have been conducted by constructing large integrated modules for outdoor durability tests. These modules, as well as the laboratory-made cell of top efficiency, employed a glass substrate $\left(\mathrm{SnO}_{2}\right.$-coated transparent conductive glass) and have shown thousands hours of lifetime by accelerated tests under exposure to sunlight and high temperatures $\left(60-85^{\circ} \mathrm{C}\right)$ [5-6]. The efficiency and lifetime, however, seems still not satisfactory to compete with the robust solid-state solar cells. For these reasons, our group has focused on drawing the low-cost merit of DSSC as much as possible by improving the structure and manufacture process of the cell. A solution to this is to realize a flexible DSSC fabricated on a plastic film substrate. This approach leads to minimizing the production cost by using a roll-to-roll printing method based on a low-temperature coating process. Such a process takes the place of the high-temperature sintering process which has been required to the conventional glass-based DSSC. Apart from the plastic film for substrates, use of polymer materials help to realize printable processes for formation of electronically active layers. 
In industrial applications of DSSC, a rapidly growing field that needs solar power is consumer electronics backed by IT technologies. The design of thin, lightweight, flexible body of DSSC opens the way especially to the installation of power sources for portable devices, where use of solar power reduces consumption of secondary batteries. In the aspect of durability, plastic devices generally have shorter lifetimes than glass-based ones. Nevertheless, they attract potential users for outdoor long-term installment since the low-cost device can permit the user repeated exchange of the device without a risk of large investment. Primary requirement to work with plastic materials is to prepare printable materials (inks or pastes) that form a solid-state conductive film on plastic at processing temperatures below $150^{\circ} \mathrm{C}$. In addition to the cost issue, it is strictly required that high conversion efficiency and stability be ensured on a mechanically flexible body of device. This article will therefore describe on important printable materials and technologies associated with construction of plastic DSSCs.

\section{Low-temperature processes for plastic DSSC}

Low-temperature preparation of adherent mesoporous semiconductor films is primarily required for fabrication of plastic electrodes. Here, special care should also be taken for handling of a transparent conductive layer that should exhibit a high conductivity for lateral electron transport on a transformable plastic surface. Essentially very low surface electric resistance $\left(<15 \mathrm{ohm}\right.$ square $\left.^{-1}\right)$ is required for the electrode of solar cells. For this, indium-tin-oxide (ITO) is a sole material available for low-temperature vacuum deposition on a plastic sheet. The ITO film, however, is chemically unstable against exposure to low $\mathrm{pH}(<4)$ so that use of acidic compounds for semiconductor treatment can not be applied. This indicates that coating of semiconductor, such as $\mathrm{TiO}_{2}, \mathrm{ZnO}$, needs special chemical and/or physical methods.

After having explored methods of making a plastic photoelectrode for DSSC such as electrophoretical deposition of $\mathrm{TiO}_{2}$ nanoparticle [7], microwave-based thermal treatment [8], and UV light irradiation [9], we have reached a best method for reinforcement of inter-particle connection under low temperature by way of developing a special $\mathrm{TiO}_{2}$ coating paste. In order for the semiconductor coating paste to meet low-temperatures film preparation and to achieve high photoelectric performance, some crucial points should be taken into account. It is desirable that use of a binder material, which ensures a sufficient viscosity for printing, should be omitted. Any organic (mostly polymer) binder can block carrier transport between particles in a resultant dry film. Despite the absence of binder, the liquid paste should have good affinity to the surface of a plastic substrate, which is often hydrophobic. The liquid components of the paste should be completely eliminated by evaporation at low temperature $(<150$ $\left.{ }^{\circ} \mathrm{C}\right)$. Finally, all components of the paste should be inert against the corrosion of the conductive layer (ITO, etc.). We have prepared a viscous suspension of nanocrystalline $\mathrm{TiO}_{2}$, which is suitable for doctor-blade coating or screen printing on a ITO-plastic sheet [10]. A film of polyethylene naphthalate (PEN, $T_{\mathrm{g}}$ of $121^{\circ} \mathrm{C}$ ) film was chosen as a plastic substrate, which bears ITO conductive layer of $13 \mathrm{ohm}$ square ${ }^{-1}$. A binder-free type $\mathrm{TiO}_{2}$ paste was prepared which comprises highly crystalline $\mathrm{TiO}_{2}$ nano-particles well-dispersed in a mixture of water and tert-butanol in the presence of brookite- $\mathrm{TiO}_{\mathrm{x}}$ aqueous sol as an interconnection cement agent. After optimization, a viscous coating paste with sufficiently high viscosity of $2000 \mathrm{mPs}$ was obtained in which $\mathrm{TiO}_{2}$ is the sole solid component. With this binder-free paste, $\mathrm{a} \mathrm{TiO}_{2}$ film is dried at $100-150^{\circ} \mathrm{C}$ for water elimination and immediately subjected to dye adsorption. On heating of a film of the binder-free $\mathrm{TiO}_{2}$ paste, particle connection (necking) and formation of a mesoporous structure occur by dehydration condensation reaction following formation of hydrogen-bonded network. The best composition of the binder-free paste for printing applications, published elsewhere [10].

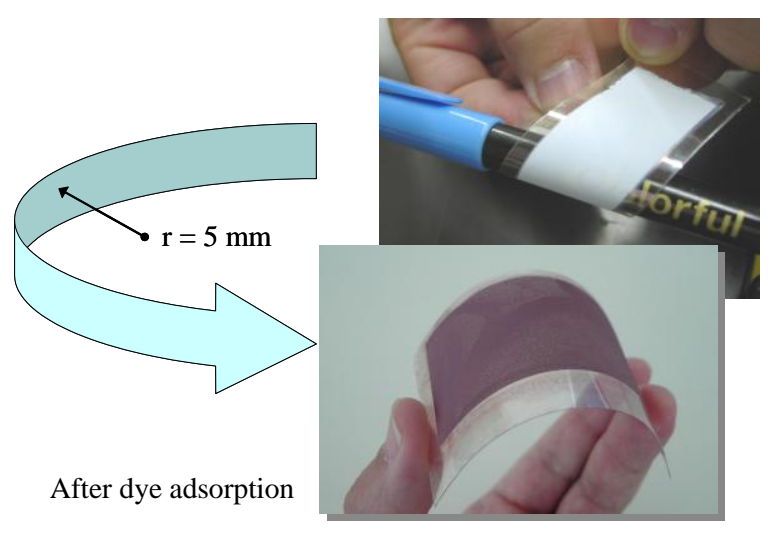

Fig. 1 Mesoporous $\mathrm{TiO}_{2}$ layer coated on ITO-PET film. It demonstrates high adhesion strength against exfoliation up to curvature of $1 / 5 \mathrm{~mm}^{-1}$ 


\section{Photovoltaic characteristics of dye-sensitized $\mathrm{TiO}_{2}$ plastic electrodes}

After coating the mesoporous $\mathrm{TiO}_{2}$ layer, electrode preparation and cell fabrication basically follows conventional processes except for the use of flexible films as substrates. $\mathrm{A} \mathrm{TiO}_{2}$ film of thickness of 3-10 $\mu \mathrm{m}$ was coated on ITO-PEN film. This thickness is much thinner than those used on glass substrate $(10-20 \mu \mathrm{m})$. With thinner films high mechanical stability and adhesion of the $\mathrm{TiO}_{2}$ layer on a flexible surface is ensured. On the other hand, kind of dye sensitizer should be optimized to have sufficiently high extinction coefficient to harvest incident light. With use of a conventional $\mathrm{Ru}$ complex dye, N719, as the sensitizer, and dye soaking for sensitization at $40^{\circ} \mathrm{C}$ for one hour, red plastic electrode with high anti-exfoliation stability was obtained as is exhibited in Fig. 1. The photovoltaic activity of the electrode was examined by combining the dye-sensitized ITO-PEN electrode with Pt-sputtered FTO glass counterelectrode to compose a miniature test cell with $0.24 \mathrm{~cm}^{2}$ irradiation area. Composition of the liquid electrolyte was typically LiI $(0.4 \mathrm{M})$, tetrabutylammonium iodide (TBAI) $(0.4 \mathrm{M}), \mathrm{I}_{2}$ $(0.04 \mathrm{M})$, 4-tert-butylpyridine (TBP) $(0.3 \mathrm{M})$ in 3-methoxypropionitrile (MPN). Photocurrent density-voltage $(I-V)$ characteristics measured under incidence of 1 sun intensity $\left(100 \mathrm{~mW} / \mathrm{cm}^{2}\right)$ showed short-circuit photocurrent density, $J_{\mathrm{sc}}$, open-circuit photovoltage, $V_{\mathrm{oc}}$, and overall efficiency $\eta$ that tends to exhibit peaks around an average size of $60 \mathrm{~nm}$ [10]. Incident-photonto-electron conversion quantum efficiency (IPCE) measured for the N719-sensitized ITO-PEN electrode shows a maximum value around $65 \%$, which is lower than the value obtained for the sintered $\mathrm{TiO}_{2}$ glass electrode, $80-90 \%$. A typical example of $I-V$ characteristic and IPCE action spectrum is exhibited in Fig. 2. This plastic cell yielded $6.1 \%$ conversion efficiency.

Measurements of electron diffusivity (D) and electron lifetime $(\tau)$ for a N719-sensitized $\mathrm{TiO}_{2}$ film made from the binder-free paste by $120^{\circ} \mathrm{C}$ treatment demonstrated that electron diffusivity $\left(\mathrm{cm}^{2} \mathrm{~s}\right)$ is roughly half that of a sintered film prepared at $450^{\circ} \mathrm{C}$ while electron lifetime is comparable. Generally, influence of the thickness of $\mathrm{TiO}_{2}$ film on the photocurrent efficiency reflects the electron diffusion length defined as $(\mathrm{D} \tau)^{1 / 2}$. The diffusion length of the non-sintered $\mathrm{TiO}_{2}$ film is in the range of 13-15 $\mu \mathrm{m}$ depending on the external electric conditions (current density and voltage applied), while this value was more than $20 \mu \mathrm{m}$ for a sintered $\mathrm{TiO}_{2}$ sample. These facts indicate that carrier transport tends to be inefficient beyond $12 \mu \mathrm{m}$. In order to improve the photocurrent by increasing the electron diffusion length, mechanical compression of a binder-free film is known to have a significant effect in efficiency improvement. Arakawa et.al. showed that such treatment is capable of yielding efficiency close to $8 \%$ based on our binder-free $\mathrm{TiO}_{2}$ technologies [11].
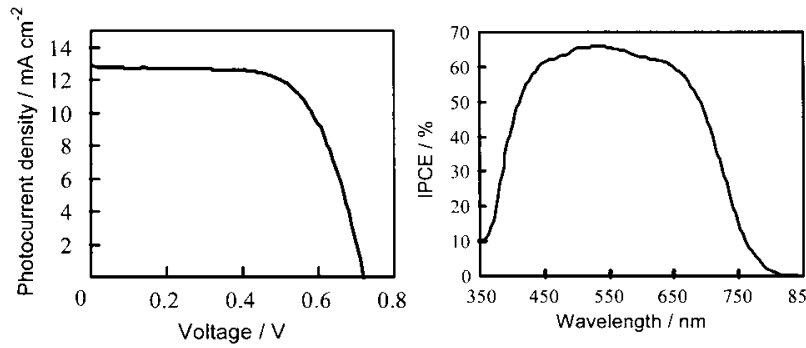

Fig. 2 Photocurrent density-voltage (I- $V$ ) characteristics for N7 19-sensitized $\mathrm{TiO}_{2}$ ITO-PEN electrode under $100 \mathrm{~mW} \mathrm{~cm}^{-2}$ incident intensity of AM1.5 simulated sunlight and IPCE action spectrum.

The use of a thinner $\mathrm{TiO}_{2}$ film in combination with a dye sensitizer which has a high extinction coefficient is expected to ensure high performance of plastic DSSC. We are currently assessing organic sensitizers such as squalilium dyes and oligothiophene type dyes, some of which prove to yield high IPCE values comparable of N719 on the $\mathrm{TiO}_{2}$ ITO-PEN electrode. Apart from organic sensitizers, we have currently employed inorganic nanocrystalline particles of quantum dot size as visible-light sensitizers for $\mathrm{TiO}_{2}$ alternative to organic dyes. Their strong light absorption ability by band-gap excitation is useful for harvesting light

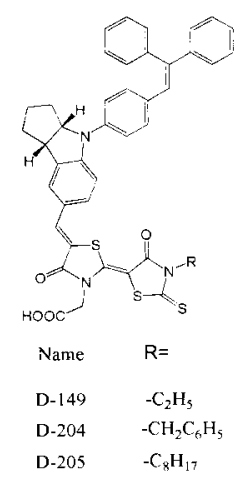

Fig. 3 Structure of indoline dyes 
with a thin mesoporous film. For example, organo-lead compound perovskite nanocrystals as quantum dots has achieved near $4 \%$ efficiency on an FTO electrode [12]. Among high-extinction organic sensitizers, indoline type dyes are recently extensively studied for their high performance close to those of $\mathrm{Ru}$ complex dyes. Typically, D102, D149, and D205, commercialized by Mitsubishi Paper Mill Ltd. as shown in Fig. 3, are promising for DSSC. We have investigated D149 on the ITO-PEN electrode. D149 has an extinction coefficient in solution of $68,000 \mathrm{~mol}^{-1} \mathrm{~cm}^{-1}$ at $530 \mathrm{~nm}$. For this dye we needed to pre-coat the ITO surface with a 15 nm-thick buffer layer of $\mathrm{TiO}_{2}$ which can suppress the back electron transfer from ITO to iodine in the electrolyte. With a thin $\mathrm{TiO}_{2}$ film of $6 \mu \mathrm{m}$ thickness in combination with an electrolyte composition of $0.4 \mathrm{M}$ LiI, $0.4 \mathrm{M}$ TBAI, $0.04 \mathrm{M} \mathrm{I}_{2}, 0.3 \mathrm{M}$ $\mathrm{N}$-methylbenzimidazole (NMB) in a mixture of acetonitrile (AN) and MPN (50/50 v/v \%), D149-sensitized plastic DSSC yields $3.7 \%$ efficiency with use of buffer layer-coated ITO-PEN electrodes [13]. Fig. 4 compares $I-V$ curves in the presence and the absence of $\mathrm{TiO}_{2}$ buffer layer. Despite high extinction coefficient, the efficiency obtained with D149 is behind those of the Ru complex families due to the shorter spectral region of the dye $(<740 \mathrm{~nm})$. However, other indoline type dye, D205, with an extinction coefficient of 53,000 $(530 \mathrm{~nm})$ and spectral response up to $770 \mathrm{~nm}$ was shown to yield conversion efficiency more than 5\% on the buffer-coated plastic electrode. This efficiency, to our knowledge, is the highest efficiency obtained with the organic dye sensitizer.

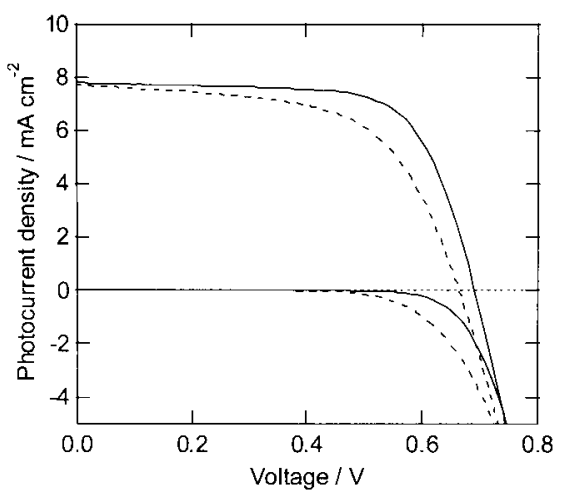

Fig. $4 I-V$ curves of plastic DSSC using D149 under 1 sun $\left(100 \mathrm{~mW} \mathrm{~cm}^{-2}\right)$ and the dark. Solid lines show a cell with the $\mathrm{TiO}_{2}$ buffer layer and dashed lines show a cell without the buffer layer.

\section{Polymer-based design for printable Counter- electrodes}

I- $V$ characteristics of DSSC are known to be significantly affected by the electrochemical activity of counterelectrodes. This activity is mainly dominated by the catalytic activity of the electrode material in addition to the intrinsic electric conductivity of the substrate. Counterelectrode widely employed in DSSCs is a platinum-coated FTO glass, in which Pt functions as a catalyst. It is well established that conductive substrate free of any catalytic coating is unable to serve as a active counterelectrode. The catalyst reduces the electrochemical overpotential for reduction of an electron acceptor in the electrolyte. This role is particularly required to the iodine/triiodide redox system. Substrate of counterelectrode need not necessarily has transparent property like FTO and ITO. Metal plates have much higher conductivity (lower resistance) than FTO. Most of metals, however, are chemically unstable against iodine especially at high temperatures. Platinum shows high catalytic activity and high stability for iodine reduction. This is why most of DSSCs are constructed on Pt-coated FTO counterelectrode.

Use of Pt however matters that Pt deposition and coating need either of vacuum deposition, high temperature or acidic treatment with $\mathrm{H}_{2} \mathrm{PtCl}_{6}$. These processes do not meet use of plastic film substrates. In addition, a vacuum-free printing method becomes important for counterelectrode. Although the amount of platinum required is very small, being much less than $10 \mathrm{~nm}$ in terms of average thickness [14], deposition of Pt on a plastic substrate can be made by vacuum sputtering which is not cost-effective in material and process time. Only a limited number of materials can replace Pt. One is a group of carbonaceous materials, the other being a group of p-type conductive polymers. The catalytic activities of these alternatives in terms of current density per unit gram of material, however, are significantly behind that of Pt. Therefore, to realize high cathodic activity, highly loadings of these materials are required. Glass-type DSSCs using carbon black-loaded counterelectrodes have been studied by Murakami, et al [15]. On a glass substrate, a thick carbon layer over thickness of $10 \mu \mathrm{m}$ was shown to be capable of producing a high efficiency of $9.1 \%$. 


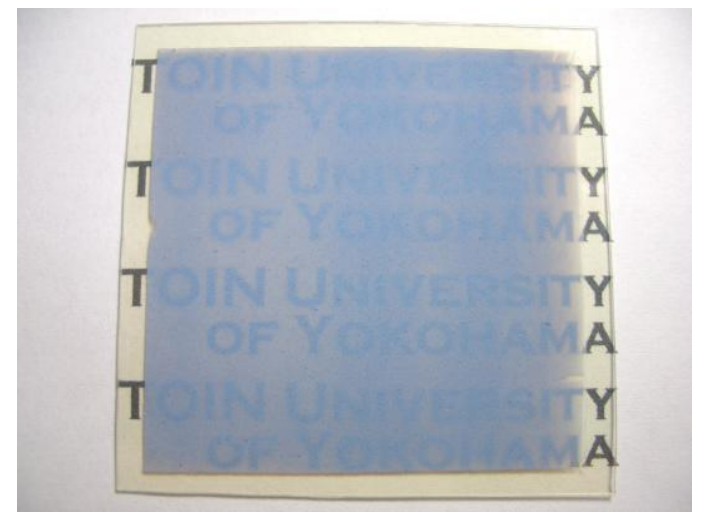

Fig. 5 Semi-transparent plastic counter- electrode bearing a mesoporous $\mathrm{TiO}_{2} \cdot \mathrm{ITO} / \mathrm{PEDOT}-\mathrm{PSS}$ composite layer on an ITO-PEN substrate.

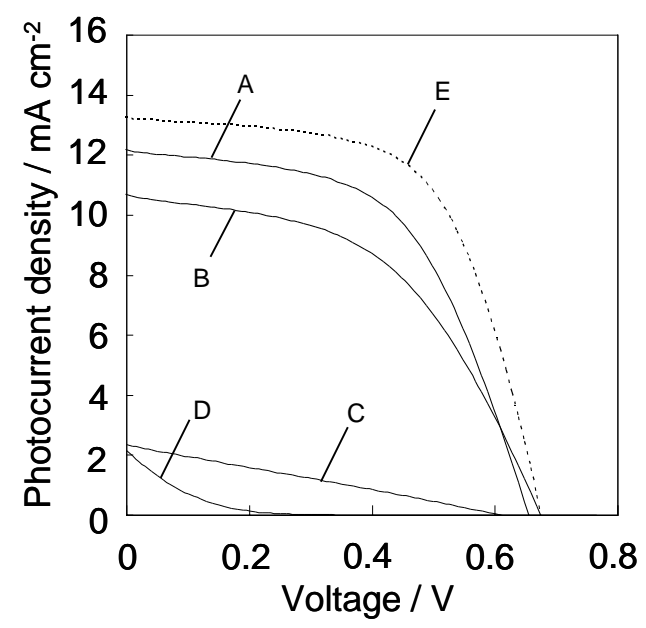

Fig. $6 I-V$ curves for plastic DSSCs using various counterelectrode materials coated on ITO-PEN plastic substrate. (A) $\mathrm{TiO}_{2}$.ITO/PEDOT-PSS film, (B) ITO/PEDOT- PSS film, (C) PEDOT-PSS film, (D) None (ITO-PEN sub- strate), (E) Sputtered Pt film on FTO-glass as a reference. Electrolyte composition, 0.4 M LiI, 0.4 M TBAI, 0.04 $\mathrm{M} \mathrm{I}_{2}$, $0.3 \mathrm{M}$ NMB in AN/MPN (1:1) (After ref. 20).

Most of electro-conductive polymers can function as cathode catalysts at the DSSC counterelectrode. A group of these polymers tends to have a p-type semiconductivity, in other words, a property as a hole conductor. This meets usability for DSSC counterelectrode. We have studied poly(3,4-ethylenedioxythiophene) doped with poly(styrenesulfonate) (PEDOT-PSS) as a printable catalyst for the DSSC counterelectrode. A coating paste was prepared by mixing PEDOT-PSS with various kinds of metal oxide nano-particles in order to immobilize a porous catalytic layer on the substrate, and to increase the active surface area. The coating paste comprised an aqueous dispersion of PEDOT-PSS (polymer concentration 1.24\%) and metal oxide nanocrystalline particles selected from a group of $\mathrm{Al}_{2} \mathrm{O}_{3}, \mathrm{SnO}_{2}, \mathrm{ZnO}$, and $\mathrm{TiO}_{2}$. Use of $\mathrm{TiO}_{2}$ particle (average size $50 \mathrm{~nm}$, specific surface area $30-40 \mathrm{~m}^{2} \mathrm{~g}^{-1}$ ) showed relatively high activity as a cathode catalyst. The PEDOT-PSS/TiO ${ }_{2}$ aqueous dispersion was further added an aqueous ITO (indium-tin-oxide) slurry (15 wt \%) to supply a paste $\left(\mathrm{TiO}_{2} \cdot\right.$ ITO/PEDOT-PSS $)$ of sufficiently high viscosity for coating. Doctor blade coating of the paste on ITO-PEN was completed by heat-drying at $110^{\circ} \mathrm{C}$ for $5 \mathrm{~min}$. The mesoporous surface of the counterelectrode shows high roughness factor (>1000) comparable with the dye-sensitized $\mathrm{TiO}_{2}$ photoelectrode.

$\mathrm{TiO}_{2} \cdot$ ITO/PEDOT-PSS films coated on ITOPEN film exhibit a pale blue to gray color and semi-transparency due to the characteristics of the nano-particles. The thickness of the $\mathrm{TiO}_{2} \cdot \mathrm{ITO} /$ PEDOT-PSS film is several micrometers to $10 \mu \mathrm{m}$. Figure 5 displays an example of a semi-transparent body of the plastic electrode.

$I-V$ characteristics of full-plastic DSSCs made on the above plastic counterelectrodes were examined. With an electrolyte composition of LiI $0.4 \mathrm{M}$, TBAI $0.4 \mathrm{M}, \mathrm{I}_{2} 0.04 \mathrm{M}, \mathrm{NMB} 0.3 \mathrm{M}$ in AN/MPN (1/1) and N719 as a dye sensitizer of the $\mathrm{TiO}_{2}$ photoanode, The I-V curves are compared in Fig. 6 for PEDOT-PSS-based counterelectrodes and a standard platinum sputtered electrode. Clearly shown is that ITO free of catalytic material lacks activity for $\mathrm{I}_{3}^{-}$reduction. The non-porous PEDOT-PSS film on ITO-PEN is still insufficient to enhance $I-V$ performance of the cell yielding a low short-circuit photocurrent density $\left(J_{\text {sc }}\right)$. Fairly high performance was obtained with ITO/PEDOT-PSS and $\mathrm{TiO}_{2}$-ITO/PEDOT-PSS films, both having porous surfaces. The energy conversion efficiency of the PEDOT-PSS-based cell reached $4.38 \%$ [16], which approaches the level of a cell using a sputtered Pt-coated FTO glass electrode, $5.41 \%$. Role of oxide nano-particles in the mesoporous counterelectrode is to create large surface area for promoting the catalytic reaction activity.

A film of PEDOT derivatives can be also immobilized by means of electrodeposition [17]. Poly(3,3-diethyl-3,4-dihydro-2H-thieno-[3,4-b][1,4 ]dioxepine) (PPDOT-Et2) was polymerized on ITO-PEN from 3,4-(2',2'-diethylpropylene)dioxythiophene as a monomer in a $10 \mathrm{mM}$ 
acetonitrile solution with $\mathrm{LiClO}_{4}$. The PPDOT-Et2 film showed a wire-like and highly porous structure due to the steric effect of the monomer [17]. This counterelectrode proved to be highly transparent.
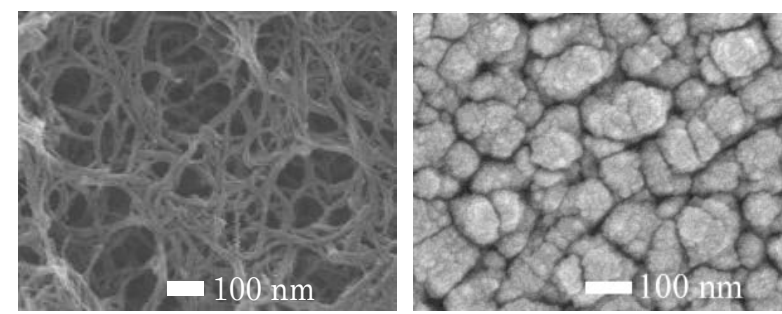

Fig. 7 SEM morphologies for a PPDOT-Et2 film prepared with deposition capacities of $40 \mathrm{mC} / \mathrm{cm}^{2}$. (left) in comparison with a sample of sputtered $\mathrm{Pt}$ film (right).

Surface morphology of the electrodeposited PPDOT-Et 2 film observed by SEM is characterized as a random and highly porous network of polymer fibres, as shown in Fig. 7. These observations employed FTO glass as the substrate for electrodeposition. ITO-coated plastic substrate can also be used for electrodeposition under the same potentiostatic conditions for polymerization. The PPDOT-Et2 counterelectrode shows excellent performance in comparison with Pt-sputtered electrodes. Fig. 8 shows IPCE action spectra for DSSCs comprising a N719-sensitized ITO-PEN electrode and PPDOT-Et2-based FTO glass counterelectrodes. IPCE spectra of cells using both conterelectodes show an equivalent performance with a maximum of about $60 \%$ at $530 \mathrm{~nm}$.

Fabrication of counterelectrode by simple

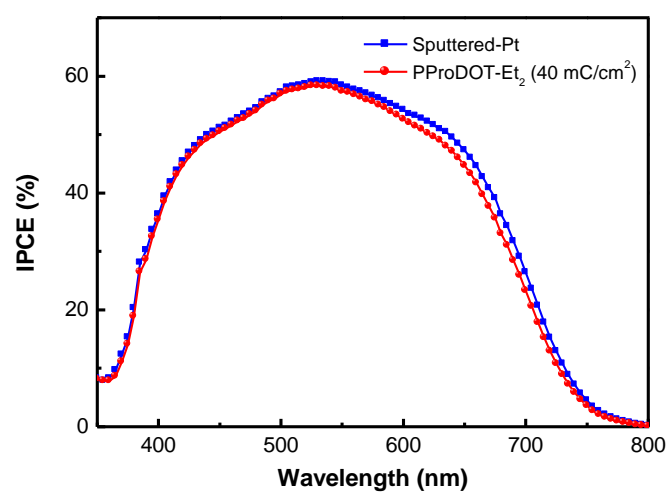

Fig. 8 Comparison of the IPCE spectra for plastic DSSCs based on PPDOT-Et2 and Pt counter electrodes (After ref. 17). coating processes using PEDOT-based printable pastes as described here is an important key for the DSSC manufacture. There are several merits for the technology. First, a simple printable process for counterelectrode fabrication without vacuum and high temperature is realized. Second, a transparent counterelectrode (cathode) can be designed for fabrication of a bifacial-type flexible photovoltaic cell in combination with a plastic dye-sensitized electrode (anode). Third, such method leads to a large cost reduction with use of low cost materials.

\section{Polymer-based solidification of DSSCs}

Other important applications of polymer materials and conductive polymers are seen in solidification of the liquid-junction structure of DSSC. As an electrochemical power device, DSSC has a similar sandwich structure to commercial batteries like lithium-ion batteries. It is a well-established manner to use a thin polymer gel electrolyte layer for these batteries for safety issue. DSSC has also been made into a quasi-solid-state cell with use of polymer gel electrolytes in terms of a mixture of organic liquid electrolyte and polymer as a matrix [18]. Other method for solidification is to use polymer conductor as a carrier transporter, especially for hole conduction. Polymer hole conductors are expected to replace the liquid electrolyte layer by bridging the dye molecules and counterelectrode. We showed that one of such replacement can be made by using poly( $N$-vinyl-carbazole) (PVK) as a hole conductor [19]. In this experiment, however, there is always difficulty in filling the interior of mesoporous $\mathrm{TiO}_{2}$ with solid materials. As an alternative to PVK, we filled the interior with potasium iodide as a solid-state redox compound that can be incorporated by soaking with a liquid solution of the salt. The PVK-based DSSC, constructed on glass substrates, gave efficiency of $2.4 \%$ [19]. Secondly, semiconductivity of polymer conductor can be utilized to rectify the carrier transport (hole transfer) at the electrochemical interface. This concept is similar to the above application to counterelectrode. In our attempt to solidify the electrolyte layer with conductive carbon materials, we have used polyaniline (PA)-coated carbon black (PACB), which was made into junction with a dye-sensitized $\mathrm{TiO}_{2}$ mesoporous layer, in which an ionic liquid was used to fill the interior. Without the coating of PA carbon layer causes back electron transfer from dye to the carbon surface (hole injection from carbon to dye). The 
presence of PA as a p-type barrier can rectify this unidirectional carrier transport at the carbon-dye interface. The quasi-solidified DSSC, sensitized by N719 achieved 3.5 and $4.1 \%$ efficiency for light intensities of 100 and $23 \mathrm{~mW} \mathrm{~cm}$, respectively [20]. The details of the carbon/polymer-based solidification study are reviewed in elsewhere [21].

\section{Fabrication of large-area full-plastic DSSC modules}

Development of utility-type DSSC has been subject of intense study for proof-of-concept test of outdoor performance and durability. DSSC modules of series DC connection have been developed by many groups using FTO glass electrodes [22-25], while a few groups have conducted fabrication of DSSC modules of plastic configuration. We have studied fabrication of full-plastic modules based on the above printing technologies. For applications to consumer electronics, for example, DC voltage of higher than $5 \mathrm{~V}$ is usually needed for powering electric devices with secondary batteries such as lithium ion-based ones. For the open-circuit voltage of DSSCs is in the range of $0.6-0.85 \mathrm{~V}$, electrical connection of unit cells become primarily necessary. A method of electrical DC connection that we have previously tried is that long strip-shaped unit cells with a width of $1 \mathrm{~cm}$ are connected at the long side. The number of unit cells connected in this fashion depends on the output voltage required. Unit cells were fabricated on ITO-PEN films. Conductive Ag grids for current-collecting structure were mounted also by low-temperature process $\left(<120^{\circ} \mathrm{C}\right)$. A hot-melt type sealer (polymerizable material) which combines two plastic substrates and prevents leaking of electrolyte was specially developed to work with temperature around $120^{\circ} \mathrm{C}$. Various electrolyte compositions were investigated for module construction. A full-plastic DSSC module of square $30 \times 30 \mathrm{~cm}$ with series DC connection of 10 unit cells (weight $60 \mathrm{~g}$, thickness about $450 \mu \mathrm{m}$ ) $[26,27]$ was assembled, which employs a highly transparent counterelectrode bearing a micro-scale network of Ti-Pt metal alloy as a cathode catalyst [14]. This Ti-based alloy film shows high resistively against corrosion by iodine. The module generates $7.2 \mathrm{~V}$ as $V_{\mathrm{oc}}$ and $250-300 \mathrm{~mA}$ as short-circuit current under exposure to 1 sun (100 $\mathrm{mW} \mathrm{cm}^{-2}$ ). This sample showed capability of powering a commercial mobile phone directly under outdoor sun light.

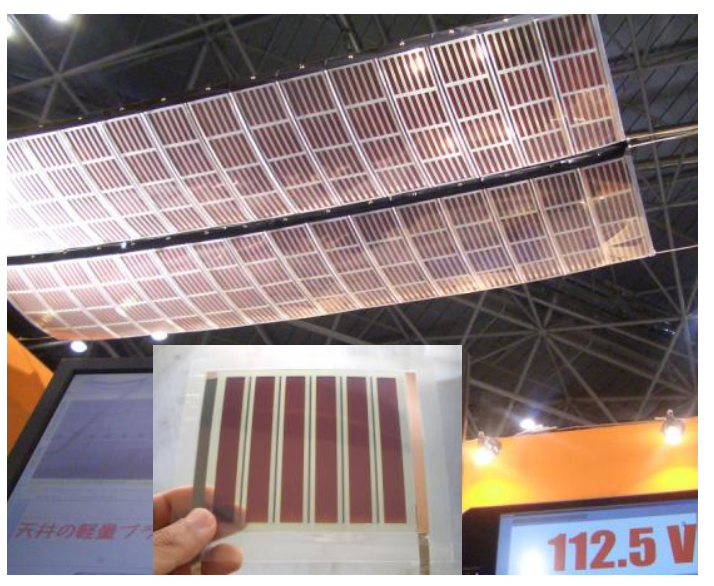

Fig. 9 Integrated full-plastic DSSC module exhibited in PVEXPO 2008 (Tokyo), producing > DC 110V under indoor illumination. Inserted is the sub-module of a square $10 \times 10 \mathrm{~cm}$ size comprising DC connection of 6 cells.

Using these modules we could confirm an advantage of DSSC over other types of commercial solid-state photovoltaic device, particularly, crystalline $\mathrm{Si}$ - based devices in respects of photo-responsibity and utilization of low-intensity light and weak diffused light. Photovoltage generated by DSSC is fairly stable in amplitude against the change of light intensity and can be maintained even in exposure to weak indoor illumination, which is normally two orders of magnitude lower than sunlight. It is noted that conversion efficiency of visible-light sensitized DSSC has high conversion efficiency, twice that respective to the sunlight spectrum, to light sources such as fluorescent light.

Durability tests for plastic cell and modules were carried out in an accelerated condition under continuous exposure to high temperatures and 1-sun irradiation [26]. With aged cells which employed N719 sensitizer, we found that lithium iodide (LiI) causes a reaction with ITO and leads to deterioration of the cell performance. Durability of plastic $\mathrm{TiO}_{2}$ electrodes was found to be significantly improved by using LiI-free electrolyte. A LiI-free electrolyte comprising, $\mathrm{I}_{2} 0.04 \mathrm{M}$, TBAI $0.4 \mathrm{M}, \mathrm{NMB} 0.3 \mathrm{M}$ in MPN/GBL (1/1) improved a cell life up to more than $220 \mathrm{~h}$ under continuous exposure to $55^{\circ} \mathrm{C}$ and humidity of $95 \%$. A similar durability was reproduced with a large full-plastic cell with $10 \times 10 \mathrm{~cm}$ in size having a series connection of 6 cells. Durability test conducted under continuous exposure to 1 sun with a solar simulator and temperature of $50^{\circ} \mathrm{C}$ showed a reduction of initial cell efficiency to half value after 
aging of $880 \mathrm{~h}$. A main reason for degradation is associated with the presence of water. The current expectation is that further improvements on electrolyte composition in combination with the use of protection (barrier) layers against water penetration will increase drastically the cell lifetime.

Based on the above improvements, a large integrated plastic module with $1 \mathrm{~m} \times 2 \mathrm{~m}$ square in size and $0.5 \mathrm{~mm}$ in thickness was constructed by combining 96 sheets of a flexible sub-module having a standard size of $10 \times 10 \mathrm{~cm}$. This module, as shown in Fig. 10, has been exhibited for proof-of-concept test in PVEXPO 2008 in Tokyo. Being flexible and lightweight $\left(0.8 \mathrm{~kg} \mathrm{~m}^{-2}\right)$. The module generates a stable DC voltage more than 110 V. Plastic DSSC modules also showed excellent performance in utilizing (absorbing) light incident to the module surface with shallow angles (high incident angles). This advantage is due to low refractive index and low optical reflectivity of dye-coated mesoporous layers compared to conventional solid-state solar cells in addition to low reflection property of the plastic surface.

\section{Summary}

Method of fabricating dye-sensitized DSSCs on plastic substrates by low-temperature printing methods is described in particular with focus on applications of polymer materials to the flexible electrode construction. The goal of developing printable materials and technologies is not only to realize high-speed and low-cost manufacture processes, but also to meet versatile demands from of users who need freely designed and fine patterns of electrode. The combination of plastic substrates and screen printing is one of the best suited means for this purpose. For roll-to-roll printing processes, solidification or quasi-solidification of liquid electrolyte layers is most important. Improvement of the plastic cell to this goal will contribute to the innovation of low-cost, green photovoltaic devices.

\section{Acknowledgments}

The authors thank New Energy and Industrial Technology Development Organization (NEDO) and Ministry of Economy, Trade, and Industry (METI), Japan for supporting in part the development of DSSC. Thanks are also due to Pro. Ho of Taiwan National University for his cooperation in counterelectrode preparation.

\section{References}

1. M. Grätzel, Chem. Lett., 34, 8(2005).

2. Y. Chiba, A. Islam, Y. Watanabe, R. Komiya, N. Koide, and L. Han, J. J. Appl. Phys., 45, L638 (2006)

3. C. -Y. Chen, M. Wang, J. -Ying Li, N. Pootrakulchote, L. Alibabaei, C. Ngoc-le, J. D. Decoppet, J. -H. Tsai, C. Grätzel, C. -G. Wu, S. M. Zakeeruddin, and M. Grätzel, ACS Nano, 3, 3103(2009).

4. Md. K. Nazeeruddin, P. Pechy, and M. Grätzel, J. Chem. Commun. 1705 , 1997; P. Wang, S. M. Zakeerruddin, P. Comte, R. Charvet, R. Humphry-Baker, and M. Grätzel, J. Phys. Chem. B., 107, 14336(2003); P. Wang, C. Klein, R. Humphry-Baker, S. M. Zakeerruddin, and M. Grätzel, J. Am. Chem. Soc., 127, 808(2005).

5. N. Kato, Y. Takeda, K. Higuchi, A. Takeuchi, E. Sudo, H. Tanaka, T. Motohiro, T. Sano, and T. Toyoda, Solar Ener. Mater. Solar Cells, 93, 893(2009).

6. H. Matsui, K. Okada, T. Kitamura, and N. Tanabe, Solar Ener. Mater. Solar Cells, 93, 1110(2009).

7. T. Miyasaka and Y. Kijitori, J. Electrochem. Soc., 151, A1767(2004).

8. T. Miyasaka, Y. Kijitori1, T. N. Murakami, M. Kimura, and S. Uegusa, Chem. Lett., 31, 1250 (2002).

9. T. N. Murakami, Y. Kijitori, N. Kawashima, and T. Miyasaka, J. Photochem. Photobiol. A, 164, 187-191(2004).

10. T. Miyasaka, M. Ikegami, and Y. Kijitori, $J$. Electrochem. Soc., 154, A455 (2007).

11. T. Yamaguchi, N. Tobe, D. Matsumoto, and H. Arakawa, Chem. Comm., 4767(2007).

12. A. Kojima, K. Teshima, Y. Shirai, and T. Miyasaka, J, Am. Chem. Soc., 131, 6050(2009).

13. K. Miyoshi, M. Numao, M. Ikegami, and T. Miyasaka, Electrochemistry, 76, 158(2008).

14. M. Ikegami, K. Teshima, K. Miyoshi, T. Miyasaka, T.C. Wei, C.C. Wan, Y.Y. Wang, Appl. Phys. Lett., 90, 153122 (2007) and references therein.

15. T. N. Murakami, S. Itoh, Q. Wang, M. K. Nazeeruddin, T. Bessho, I. Cesar, P. Liska, R. Humphry-Baker, P. Comte, P. Pechy, and M. Grätzel, J. Electrochem. Soc.153, A2255(2006). 
16. T. Muto, M. Ikegami, K. Kobayashi, and T. Miyasaka, Chem. Lett., 36, 804 (2007).

17. K.-M. Lee, C.-Y. Hsu, P.-Y. Chen, M. Ikegami, T. Miyasaka, K.-C. Ho, Phys. Chem. Chem. Phys., 18, 3375(2009).

18. W. Kubo, T. Kitamura, K. Hanabusa, Y. Wada, S. Yanagida, Chem. Commun., 374 (2002); P. Wang, S. M. Zakeeruddin, I. Exnar, M. Grätzel, Chem. Commun., 2972(2002).

19. N. Ikeda and T. Miyasaka, Chem. Comm., 1886(2005).

20. N. Ikeda, K. Teshima, and T. Miyasaka, Chem. Commun., 1733, 2006.

21. T. Miyasaka, N. Ikeda, T. N. Murakami, and K. Teshima, Chem. Lett., 36, 480(2007).

22. T. Toyoda, T. Sano, J. Nakajima, S. Doi, S. Fukumoto, A. Ito, T. Tohyama, M. Yoshida, T. Kanagawa, T. Motohiro, T. Shiga, K. Higuchi, K. Tanaka, Y. Takeda, T. Fukano, N. Katoh, A.
Takeichi, K. Takechi, and M. Shiozawa, $J$. Photochem. Photobiol. A. 164, 203(2004).

23. A. Fukui, N. Fuke, R. Komiya, N. Koide, R. Yamanaka, H. Katayama, and L. Han, Appl. Phys. Express, 2, 082202(2009).

24. A. Hinsch, H. Brandt, W. Veurman, S. Hemming, M. Nittel, U. Würfel, P. Putyra, C. Lang-Koetz, M. Stabe, S. Beuker, and K. Fichter, Solar Ener. Mater. Solar Cells, 93, 820(2009).

25. DSSC manufactures, for examples, Dyesol Ltd., http://www.dyesol.com/; Solaronix SA, http://www.solaronix.com/.

26. M. Ikegami, J. Suzuki, K. Teshima, M. Kawaraya, and T. Miyasaka, Solar Ener. Mater. Solar Cells, 93, 836(2009).

27. T. Miyasaka, Y. Kijitori, and M. Ikegami, Electrochemistry, 75, 2(2007). 